\title{
Positional Effects on the Characterization of Ejectives in Waima'a
}

\author{
Mary Stevens ${ }^{1}$, John Hajek ${ }^{1}$ \\ ${ }^{1}$ School of Languages and Linguistics, University of Melbourne, Australia \\ mes@unimelb.edu.au, j.hajek@unimelb.edu.au
}

\begin{abstract}
This paper presents results from an ongoing investigation into stop consonants in Waima'a, focusing on the issue of tense v. lax ejectives. Sources tend to describe ejectives in a given language as either tense or lax; however ejectives in Waima'a, do not fit squarely into either category [4]. Here we compare ejectives in word-initial and word-medial contexts, to specifically address the role of word-position in the tense/lax distinction. Results show that word-position affects the duration of all stop types analyzed, i.e. unaspirated, postaspirated, \& ejective stops. Variability amongst the ejective tokens suggests that the notion of a tense/lax dichotomy should be replaced instead with that of a tense/lax continuum. Index Terms: ejectives, stop contrasts, tense, lax, Waima'a
\end{abstract}

\section{Introduction: tense and lax ejectives}

It has been suggested that ejectives may fall into two classes, tense (also: strong, stiff) v. lax (also: weak, slack) in different languages, e.g. [2], [5], [9]. These two types can be distinguished in terms of VOT duration, and contextual creak (on the following vowel). Tense ejectives have a relatively long VOT $(>60 \mathrm{~ms})$ and modal voice on the following vowel; lax ejectives have a short VOT $(<60 \mathrm{~ms})$ and a creaky following vowel, while perceptually, the latter can also be difficult to distinguish from unaspirated stops [2]. Other, secondary cues to the tense and lax distinction, e.g. pitch and amplitude rise, have been discussed, although their role is less clear (see e.g. [10]).

While it has also been suggested that languages have either tense (e.g. Navajo) or lax (e.g. Hausa) ejectives, not both, somewhat exceptionally, Dakelh is argued to have both kinds in its system: based on the suggested VOT threshold of $60 \mathrm{~ms}$, [2] proposed that the "simple ejectives" /t' k'/ are lax, and the "complex ejectives" /ts' tl' ts'/ are tense. In other words "ejectives tend to fall into natural classes in terms of strength, based on aerodynamic restrictions involved in their production".

Methodological differences between studies on ejectives can make them difficult to reliably cross-compare. For example, a study of ejectives in Witsuwit'en [10] involved segments recorded in utterance-initial position, whereas for Ingush, ejective tokens were recorded within carrier phrases [9]. These differences do not allow the (potential) impact of prosodic boundaries on ejectives to be controlled for. The use of ejectives in utterance-initial position, in particular, means that closure duration cannot be measured. Morever, the role of closure duration, if any, in the tense/lax ejective distinction has not been specifically addressed in any previous study.

\subsection{Ejectives in Waima'a}

A number of potential criteria have been proposed in these earlier sources to distinguish between ejectives and other stop types. In Waima'a, an Austronesian language spoken in East Timor, ejective stops are distinguished from their unaspirated /(p) $\mathrm{t} \mathrm{k} /$ and aspirated $/ \mathrm{p}^{\mathrm{h}} \mathrm{t}^{\mathrm{h}} \mathrm{k}^{\mathrm{h}} /$ counterparts by VOT durations (intermediate between unaspirated and aspirated), and overall $\mathrm{C}$ durations (i.e. closure + VOT). Aspirated stops have the longest VOT and overall durations, ejectives have intermediate VOT and overall durations, and plain unaspirated stops are the shortest on both measures. In these respects Waima'a ejectives pattern well with ejectives in other languages, as noted by [4], [8].

As to whether they can be classified as tense or lax, recall from $\S 1$ that 'simple' $/ \mathrm{t}^{\prime} \mathrm{k} /$ are lax in Dakelh, because they show VOT durations below 60ms (whereas 'complex' /ts' tl' $\mathrm{t} f$ '/ are tense). Waima'a has only the 'simple' /p' t' $\mathrm{k}$ '/ ejectives (following [2]) which may suggest they are lax. However, the available evidence is inconclusive. Based on VOT values for Waima'a ejectives, dental / $t$ '/ is weak, velar $/ \mathrm{k}^{\prime} /$ is borderline, and the status of $/ \mathrm{p} /$ is unclear for two reasons [4]. First, there are no cross-linguistic duration values for $/ \mathrm{p}^{\prime} /$ with which to compare Waima'a $/ \mathrm{p}^{\prime} /$, because languages with ejectives often do not have them at bilabial place (e.g. [2], [3], [9]). Second, within Waima'a, ejective /p'/ cannot be compared with unaspirated $/ \mathrm{p} /$, because the latter only occurs in recent loans from Portuguese, and is highly unstable.

Ejectives in Waima'a are no more neatly classified based on the quality of the following vowel: [4] found creak on some tokens (indicative of lax ejectives), but not consistently.

These measures suggest that, for Waima'a, either (a) the distinction between tense and lax ejectives does not apply; or (b) the realization of /p' t' k'/ as tense or lax is conditioned by a factor as yet unaccounted for.

Earlier studies on ejectives present data based on one word-position only (typically word-initial position), e.g. [3], [9], [10]. Therefore, while word-position, e.g. through wordand domain-initial strengthening [6], is well known to affect the realization of other stop types, its effect on ejectives is less clear.

The suggested VOT threshold value of $60 \mathrm{~ms}$ to distinguish tense and lax ejectives is claimed by [2] to hold across word-position (initial v. intervocalic) in Dakelh. However, no duration values for ejectives across different word-positions were presented in that source.

Based on an analysis of ejectives in Chaha, [3] argued that the realization of ejectives is not conditioned by wordposition alone. Comparing ejectives in word-medial clusters (e.g. $/ k^{\prime} \cdot t^{\prime} /$ v. $/ t^{\prime} \cdot k^{\prime} /$ v. $\left./ k \cdot t^{\prime} /\right)$, [3] found that the degree of consonant reduction was dependent on place of articulation. However, ejectives in other word-positions were not examined in that study, and the tense/lax distinction for ejectives was not specifically addressed.

\subsection{Aims of this study}

In this paper we investigate the potential role of word-position in the realization of /p' t' k'/ in Waima'a. We hypothesize that ejectives may be realized as lax in word-medial contexts but tense in word-initial through word-initial strengthening, following [6]. We focus on the three main phonetic correlates 
of the tense/lax distinction: closure duration, VOT (and both combined), as well as the quality of the following vowel.

Under this hypothesis, ejective tokens would have higher VOT and closure values in word-initial than in word-medial contexts. Ejectives in word-initial and word-medial contexts would also differ according to the quality of the following vowel: the former would be more likely to show modal voice; creaky voice would be more likely for the latter as a result of possibly laxer articulation and laryngeal control.

Together, this temporal and spectral evidence will help to underline the difficulties in classifying ejectives in Waima'a as tense or lax. It will also help our understanding of ejectives more generally, and address the question of whether it is useful to distinguish tense and lax ejectives as two separate categories across languages.

\section{Data and Methods}

The data consist of target words read in a simple carrier sentence by one adult male speaker of Waima'a, recorded in a laboratory setting using a high quality microphone and DAT recorder. While the investigation is limited by the use of only one speaker subject at this stage, we note that other experimental studies on ejectives also involve single speaker studies (e.g. [1], [9]).

The target words fall into two groups: (a) those with a voiceless stop (unaspirated, aspirated or ejective) in wordinitial position, e.g. t'ali 'chew'; and (b) those with the causative prefix $\mathrm{ra}$ - followed by a voiceless stop e.g. rat'ali 'make chew'. This allowed voiceless stops to be recorded in both word-initial and word-medial contexts.

The frame ehe "say "was used, so that the stop was always in post-vocalic position and closure duration could be measured.

All target consonants used for this study preceded low central /a/, except the velar ejective $/ \mathrm{k}^{\prime} /$ token which preceded back /o/ in both word-medial and word-initial contexts (no words were available for $/ \mathrm{k}^{\prime} /+/ \mathrm{a} /$ in both contexts). Notably, for the dental ejective $/ t^{\prime} /$, the target word $t^{\prime}$ ali 'chew' replaces earlier t'iba 'deep', allowing us to better control for the effect of vowel height [4]. Up to 5 repetitions were recorded for each word, giving 66 tokens in total which were distributed as follows:

Table 1. Number of tokens according to place and manner of articulation, and position in the word.

\begin{tabular}{|c|c|c|c|}
\hline & Word-initial & Word-medial & Total \\
\hline$/ \mathrm{p}^{\prime} /$ & 5 & 5 & 10 \\
$/ \mathrm{t} ' /$ & 4 & 4 & 8 \\
$/ \mathrm{k} /$ & 4 & 4 & 8 \\
$/ \mathrm{ph} /$ & 4 & 4 & 8 \\
$/ \mathrm{th} /$ & 4 & 4 & 8 \\
$/ \mathrm{kh} /$ & 4 & 4 & 8 \\
$/ \mathrm{p} /$ & - & - & - \\
$\mathrm{t} /$ & 4 & 4 & 8 \\
$/ \mathrm{k} /$ & 4 & 4 & 8 \\
Total & 33 & 33 & 66 \\
\hline
\end{tabular}

Unaspirated bilabial /p/, an unstable and rare loan which alternates with $/ \mathrm{p}^{\mathrm{h}}, \mathrm{f}, \mathrm{b} /$, was excluded from the study.

For each token, using spectrographic and waveform displays within the Praat program, the duration of the closure period and of the VOT were measured. VOT, in particular, was measured from the start of the oral release burst to the first glottal pulse associated with the vowel, following [1],
[7], [10] (see [4], [8] for more detail on the measurement criteria).

For the subset of ejective stops /p' t' k'/, the quality of the surrounding vowels was also noted, through direct visual inspection, following [9].

\section{Results \& discussion}

\subsection{Word position and closure duration}

We first examine the effect of word-position on closure duration for the ejective stops. Table 2 shows the closure duration values for voiceless stops (ejective, aspirated, unaspirated) in word-initial (WI) and word-medial (WM) contexts, as well as the difference between the two (as a percentage).

Table 2. Closure durations (average $(x)$ and standard deviation ( $S D)$, in $\mathrm{ms}$ ) for ejective, post-aspirated and unaspirated stops. Values are for word-initial (WI) and word-medial (WM) contexts, and the percentage increase at word-initial position.

\begin{tabular}{cccccc}
\hline & \multicolumn{2}{c}{ WI } & \multicolumn{2}{c}{ WM } & $\begin{array}{c}\text { WI-WM } \\
\mathbf{( \% )}\end{array}$ \\
\hline & $\mathbf{x}$ & SD & $\mathbf{x}$ & SD & \\
\hline$/ \mathrm{p}^{\prime} /$ & 133.5 & 11 & 129.2 & 17 & 3.3 \\
$/ \mathrm{t}^{\prime} /$ & 147.0 & 21 & 126.8 & 15 & 15.9 \\
$/ \mathrm{k}^{\prime} /$ & 119.5 & 9 & 118.3 & 6 & 1.0 \\
\hline$/ \mathbf{p}^{\prime} \mathbf{t}^{\prime} \mathbf{~ k} /$ & $\mathbf{1 3 3 . 3}$ & $\mathbf{1 4}$ & $\mathbf{1 2 4 . 8}$ & $\mathbf{1 3}$ & $\mathbf{6 . 9 \%}$ \\
\hline$/ \mathrm{p}^{\mathrm{h} /}$ & 200.7 & 73 & 126.8 & 9 & 58.3 \\
$/ \mathrm{t}^{\mathrm{h} /}$ & 123.2 & 4 & 118.3 & 2 & 4.1 \\
$/ \mathrm{k}^{\mathrm{h} /}$ & 105.0 & 3 & 112.3 & 7 & -6.5 \\
\hline$/ \mathbf{p h ~ t h ~} \mathbf{~ k h} /$ & $\mathbf{1 4 3 . 0}$ & $\mathbf{2 7}$ & $\mathbf{1 1 9 . 1}$ & $\mathbf{6}$ & $\mathbf{2 0 . 0 \%}$ \\
\hline$/ \mathrm{t} /$ & 123.2 & 7 & 114.7 & 7 & 7.4 \\
$/ \mathrm{k} /$ & 140.1 & 17 & 119.5 & 6 & 17.2 \\
\hline$/ \mathbf{t ~} \mathbf{k} /$ & $\mathbf{1 3 1 . 7}$ & $\mathbf{1 2}$ & $\mathbf{1 1 7 . 1}$ & $\mathbf{7}$ & $\mathbf{1 2 . 4 \%}$ \\
\hline & & & & &
\end{tabular}

Table 2 shows that word-position has an effect on closure durations. In word-initial position, the overall duration values for each stop series, i.e. ejectives, aspirated and unaspirated, are longer than those for word-medial position $(+8.6 \mathrm{~ms}$, $+23.8 \mathrm{~ms}$, $+14.6 \mathrm{~ms}$, respectively), albeit with substantial internal variation.

Within the ejective series, the effect is marked for dental $/ \mathrm{t}^{\prime} /$, which increases by $20.2 \mathrm{~ms}(15.9 \%)$, while velar $/ \mathrm{k}^{\prime} /$ and bilabial $/ \mathrm{p}^{\prime} /$ show little or no effect.

The effect of word-position on closure durations is greatest for the aspirated series, at $20.0 \%$ overall (compared to $12.4 \%$ and $6.9 \%$ for the unaspirated and ejective series, respectively). However, this increase masks the fact that postaspirated velar $/ \mathrm{k}^{\mathrm{h}} /$ is actually longer in word-medial $(112.3 \mathrm{~ms})$ than word-initial position $(105.0 \mathrm{~ms})$. At this stage it is not clear why velar $/ \mathrm{k}^{\mathrm{h}} /$ shows the opposite pattern to all other stops in Table 2, although it could be due to interaction between these closure durations and VOT, which we next examine.

\subsection{Word position and VOT duration}

Table 3, below, shows the duration values for voice onset time (VOT) for word-initial and word-medial ejective, aspirated and unaspirated stops in the corpus. 
Table 3. VOT durations (ms) for ejective, postaspirated and unaspirated stops in word-initial (WI) and word-medial (WM) contexts.

\begin{tabular}{cccccc}
\hline & \multicolumn{2}{c}{ WI } & \multicolumn{2}{c}{ WM } & $\begin{array}{c}\text { WI-WM } \\
(\mathbf{\%})\end{array}$ \\
\hline & $\mathbf{x}$ & SD & $\mathbf{x}$ & SD & \\
\hline$/ \mathrm{p}^{\prime} /$ & 36.8 & 5 & 29.4 & 5 & 25.2 \\
$/ \mathrm{t}^{\prime} /$ & 30.5 & 18 & 23.5 & 8 & 29.8 \\
$/ \mathrm{k}^{\prime} /$ & 64.6 & 21 & 52.5 & 25 & 23.0 \\
\hline$/ \mathbf{p}^{\prime} \mathbf{t}^{\prime} \mathbf{~ k} /$ & $\mathbf{4 4 . 0}$ & $\mathbf{1 5}$ & $\mathbf{3 5 . 1}$ & $\mathbf{1 3}$ & $\mathbf{2 5 . 1 \%}$ \\
\hline$/ \mathrm{p}^{\mathrm{h} /}$ & 56.9 & 5 & 62.2 & 7 & -8.5 \\
$/ \mathrm{t}^{\mathrm{h} /}$ & 96.1 & 15 & 96.1 & 18 & 0.0 \\
$/ \mathrm{k}^{\mathrm{h} /}$ & 104.2 & 19 & 106.6 & 3 & -2.3 \\
\hline$/ \mathbf{p h ~ t h ~} \mathbf{~ k h} /$ & $\mathbf{8 5 . 7}$ & $\mathbf{1 3}$ & $\mathbf{8 8 . 3}$ & $\mathbf{9}$ & $\mathbf{- 2 . 9 \%}$ \\
\hline$/ \mathrm{t} /$ & 22.2 & 5 & 22.6 & 2 & -1.8 \\
$/ \mathrm{k} /$ & 23.8 & 3 & 23.8 & 3 & 0.0 \\
\hline$/ \mathbf{t} \mathbf{~ k} /$ & $\mathbf{2 3}$ & $\mathbf{4}$ & $\mathbf{2 3 . 2}$ & $\mathbf{3}$ & $\mathbf{- 0 . 9 \%}$ \\
\hline
\end{tabular}

Turning first to the ejectives, we can see that $/ \mathrm{p}^{\prime} \mathrm{t}^{\prime} \mathrm{k}^{\prime} /$, taken together, are $8.8 \mathrm{~ms}(25.1 \%)$ longer in word-initial than wordmedial contexts. The effect of word-position is strongest for dental $/ t^{\prime} /$, which increases by $29.8 \%$ in word-initial position.

Relating these VOT values to the tense/lax threshold of $60 \mathrm{~ms}$ (cf. §1), we can see that all values fall below it - except for word-initial velar $/ \mathrm{k}^{1} /$, with a VOT of $64.6 \mathrm{~ms}$. In other words, according to word-position, velar $/ \mathrm{k}^{\prime} /$ would be categorized either as 'tense' (word-initial), or 'lax' (wordmedial). This result conflicts with that given by [2] who reported that the $60 \mathrm{~ms}$ threshold was upheld across wordpositions in Dakelh.

The VOT values in Table 3 for the aspirated and unaspirated stops do not show the same effect of word position, seen for ejectives: there are minimal if any differences, with the possible exception of $/ \mathrm{ph} /$.

Comparing across the three stop series, Table 3 shows that word-position has a marked effect only on the VOT for the ejective series in Waima'a, which increases by $25.1 \%$. While there is no difference between VOT values for ejective $/ \mathrm{t} /$ and unaspirated / $\mathrm{t} /$ word-medially, overall VOT values for ejectives remain intermediate between those of the aspirated and unaspirated stops, as noted in $\S 1.1$, and this pattern is upheld across word positions.

\subsection{Word position and overall $\mathbf{C}$ duration (closure + VOT)}

Table 4 shows the overall duration values for ejective, aspirated and unaspirated stops in the data set, for the two word-positions.

Most notable is the uniformity across stop series in terms of overall duration, which all show an increase of around $10 \%$ in word-initial position. This is in contrast to their separate components (i.e. closure and VOT, seen in Tables 2 \& 3, respectively), with much more divergent patterns, and reflects the different interactions between closure and VOT durations.

The ejective stop series $/ \mathrm{p}^{\prime} \mathrm{t}^{\prime} \mathrm{k}^{\prime} /$ is $17.4 \mathrm{~ms}$ longer in wordinitial position, reflecting the higher durations for both closure and VOT in word-initial positions, seen in Tables 2 and 3, respectively. Within the ejective stops, velar $/ \mathrm{k}^{\prime} /$ shows the highest overall duration values in both word-positions, although dental $/ \mathrm{t}^{\prime} /$ shows the greatest effect of word-position, with an increase of $27.2 \mathrm{~ms}(18.1 \%)$ word-initially.
Table 4. Overall consonant durations (closure + $V O T$, in $\mathrm{ms}$ ) for ejective, post-aspirated and unaspirated stops in word-initial (WI) and wordmedial (WM) contexts.

\begin{tabular}{cccccc}
\hline & \multicolumn{2}{c}{ WI } & \multicolumn{2}{c}{ WM } & $\begin{array}{c}\text { WI-WM } \\
(\%)\end{array}$ \\
\hline & $\mathbf{x}$ & SD & $\mathbf{x}$ & SD & \\
\hline$/ \mathrm{p}^{\prime} /$ & 170.3 & 7 & 158.6 & 14 & 7.4 \\
$/ \mathrm{t}^{\prime} /$ & 177.5 & 31 & 150.3 & 8 & 18.1 \\
$/ \mathrm{k}^{\prime} /$ & 184.2 & 35 & 170.8 & 28 & 7.8 \\
\hline$/ \mathbf{p}^{\prime} \mathbf{t}^{\prime} \mathbf{~ k} /$ & $\mathbf{1 7 7 . 3}$ & $\mathbf{2 4}$ & $\mathbf{1 5 9 . 9}$ & $\mathbf{1 7}$ & $\mathbf{1 0 . 9 \%}$ \\
\hline$/ \mathrm{p}^{\mathrm{h} /}$ & 257.7 & 73 & 189.0 & 11 & 36.3 \\
$/ \mathrm{t}^{\mathrm{h} /}$ & 219.3 & 15 & 214.4 & 17 & 2.3 \\
$/ \mathrm{k}^{\mathrm{h} /}$ & 209.2 & 21 & 218.9 & 8 & -4.4 \\
\hline$/ \mathbf{p h ~ t h ~} \mathbf{~ k h} /$ & $\mathbf{2 2 8 . 7}$ & $\mathbf{3 6}$ & $\mathbf{2 0 7 . 4}$ & $\mathbf{1 2}$ & $\mathbf{1 0 . 3 \%}$ \\
\hline$/ \mathrm{t} /$ & 145.4 & 11 & 137.3 & 9 & 5.9 \\
$/ \mathrm{k} /$ & 164.0 & 20 & 143.4 & 9 & 14.4 \\
\hline$/ \mathbf{t ~ k} /$ & $\mathbf{1 5 4 . 7}$ & $\mathbf{1 6}$ & $\mathbf{1 4 0 . 4}$ & $\mathbf{9}$ & $\mathbf{1 0 . 2 \%}$ \\
\hline & & & & &
\end{tabular}

Patterns are not as clear within the aspirated series: an overall increase of $10.3 \%$ masks considerable variation according to place of articulation. Bilabial $/ \mathrm{p}^{\mathrm{h}} /$ increases by $68.7 \mathrm{~ms}(36.3 \%)$ in word-initial position, whereas velar $/ \mathrm{k}^{\mathrm{h}} /$ shows a reduction in overall duration of $9.7 \mathrm{~ms}(-4.4 \%)$. This reduction in word-initial position reflects the shorter closure duration (cf. Table 2), which, despite the expected interaction between closure and VOT durations, was not accompanied by an increase in VOT.

Within the unaspirated series we can see that the effect of word-position is greatest for velar $/ \mathrm{k} /$, at $14.4 \%$.

Overall there appears to be no consistent interaction between place of articulation and word-position (contra [3]), at least in these Waima'a data. Amongst the ejectives, it is the dental $/ t^{\prime} /$ which shows the greatest effect of word-position, whereas within the aspirated and unaspirated series it is the bilabial $/ \mathrm{p}^{\mathrm{h}} /$, and velar $/ \mathrm{k} /$ stops, respectively.

\subsection{Word-position and vowel quality: ejectives}

Focusing on the ejective stops, a visual inspection was undertaken to determine the frequency of creaky voice. Results are listed in Table 5.

Table 5. Number of ejective tokens with creaky voice in the following vowel, according to place of articulation and word-position.

\begin{tabular}{|c|c|c|c|}
\hline & Word-initial & Word-medial & Total \\
\hline$/ \mathrm{p} \prime$ & $0 / 5$ & $0 / 5$ & $0 / 10$ \\
$/ \mathrm{t} \prime$ & $3 / 4$ & $4 / 4$ & $7 / 8$ \\
$/ \mathrm{k} \prime$ & $0 / 4$ & $0 / 4$ & $0 / 8$ \\
\hline
\end{tabular}

Creak was found only after dental / $t^{\prime} /$, occurring - in 7 of the 8 tokens, with none found after bilabial and velar ejectives. These patterns differ from earlier results for Waima'a [4], [8], which found creak on 2 velar $/ \mathrm{k}^{\prime} /$ tokens, but not on any of the dental $/ t^{\prime} /$ tokens. However, in [4] \& [5], dental $/ t^{\prime} /$ preceded high front $/ \mathrm{i} /$, while velar $/ \mathrm{k}^{\prime} /$ preceded $/ \mathrm{a} /$ (excluded for sampling difficulties from this study - see $\$ 2$ above). These differences support the claim that the occurrence of creak is dependent on the identity of the following vowel [9], and is closely associated with low central /a/, in particular. 
From Table 5, there appears to be no effect of wordposition on the frequency of creaky voice. In other words, based on the criterion of creakiness on the following vowel (cf. §1), word-position does not determine the realization of ejectives as tense (no creak) or lax (with creak). To illustrate this point, Figure 1, below, shows two repetitions of $t^{\prime} a l i$ 'chew', with an dental ejective / $t$ '/ in word-initial position.
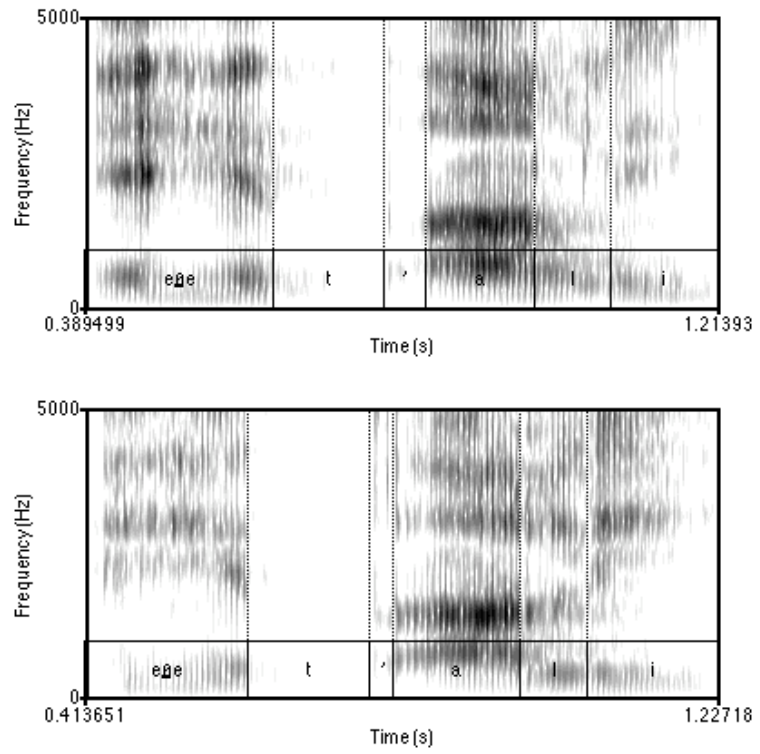

Figure 1. Two separate realizations of the word t'ali 'chew', without (top) and with creak (bottom).

The top token shows what would be classified as a tense ejective, with a relatively long VOT $(56 \mathrm{~ms})$ and no creak. The token below, on the other hand, would be classified as lax, based on the VOT value of only $21 \mathrm{~ms}$, and the clear striations in the onset of the following vowel, indicative of creaky voice. This variation within ejective tokens, even within repetitions of the same word by the same speaker, suggests that the classification of ejectives as either tense and lax is unreliable, at least if based on the criterion of voice quality.

\section{Conclusions}

Our limited investigation supports the notion that wordposition affects the realization of ejectives. Like the other stop series, they show longer closure durations in word-initial position, although the extent of the increase is less than for the aspirated and unaspirated stops. In terms of VOT, on the other hand, the effect of word-position is greatest for the ejective series, which shows an overall increase of $25.1 \%$. Overall stop duration values, (i.e. closure + VOT) patterned evenly for all three stop series, which each showed an increase of $\sim 10 \%$ in word-initial position.

In terms of the effect of these positional effects on the characterization of ejectives, we saw that velar $/ \mathrm{k}^{1 /}$ would be classified as tense in word-initial position, based on VOT values, but as lax in word-medial position. In other words, the suggested VOT threshold of $60 \mathrm{~ms}$ [2] was not upheld across word-positions in these Waima'a data.

While there was no clear effect of word-position on the realization of the following vowel (as either creaky or modal), there did appear to be an effect of ejective place of articulation (after $/ \mathrm{t} /$ only) and, when comparing our results with $[4,8]$, with vowel height: creak occurs only on /a/. The presence or absence of creak, as a criterion, did not help to classify the Waima'a ejectives as either tense or lax, as creakiness was not consistently found for all places of articulation or word-positions.

Our results show that the realization of ejectives is partly dependent on word-position, in that they show increased VOT and overall consonant duration values word-initially. However, controlling for word-position does not help to classify the Waima'a ejectives as necessarily tense or lax. Results also interact with place of articulation within the ejective series, complicating any tense/lax characterization: $/ \mathrm{t} /$ is much longer word-initially (tense) but with low VOT values (lax) and is typically followed by a creaky vowel (lax), while /p', k'/ show positional effects affecting VOT and overall duration (tense) but not closure (lax?). They show no following creak (tense), while in terms of VOT levels /p'/ is always lax, while $/ \mathrm{k}^{\prime} /$ is tense initially but lax medially.

Of the hypotheses outlined in $\S 1.1$, our results support (a); that for Waima'a, a simply binary distinction between tense and lax ejectives does not apply. Ejectives should be seen as being variably realized along a tense-lax continuum, rather than as falling simply into one of two distinct categories 'tense' or 'lax'. Along these lines, ejectives are stronger, or more tense, in word-initial than word-medial position, as are the aspirated and unaspirated voiceless stops. Researchers should also bear in mind, when investigating the tense vs lax nature of ejectives in other languages, the possible effects of word-position on their results.

\section{Acknowledgements}

The authors wish to acknowledge the support of the Australian Research Council for this research.

\section{References}

[1] Billerey-Mosier, R., "An acoustic analysis of Kiowa stops." Unpublished manuscript, UCLA, 2003.

[2] Bird, S. "Dakelh ejectives: evidence for new ways of classifying sounds". Paper delivered at LSA 2002.

[3] Coulston, R., "Ejective reduction in Chaha is conditioned by more than prosodic position". Proc. Eurospeech-2001: 365-368, 2001.

[4] Hajek, J. \& Stevens, M., "On the Acoustic Characterization of Ejective Stops in Waima'a". Proc. Interspeech 2005: 28892892, 2005.

[5] Kingston, J., The phonetics and phonology of the timing of oral and glottal events. Dissertation, University of California, 1984.

[6] Keating, P., T. Cho, C. Fougeron, and C. Hsu: "Domain-initial articulatory strengthening in four languages". In J. Local, R. Ogden, R. Temple, Phonetic Interpretation, Cambridge, Cambridge University Press: 143-161, 2003.

[7] Maddieson, I., "Phonetic universals". In W. J. Hardcastle \& J. Laver, The Handbook of Phonetic Sciences. Oxford, Blackwell: 619-639, 1997.

[8] Stevens, M. and Hajek, J., “A preliminary investigation of some acoustic characteristics of ejectives in Waima'a: VOT and closure duration". Proc. Tenth Australian International Speech Science and Technology Conference, Sydney, 2004.

[9] Warner, N., "Acoustic characteristics of ejectives in Ingush", Proc. ICSLP-96, 1525-1528, 1996.

[10] Wright, R., Hargus, S. and Davis, K., "On the categorization of ejectives: data from Witsuwit'en”. JIPA 32: 43-77, 2002. 